\title{
A glucose-dependent spatial patterning of exocytosis in human $\beta$ cells is disrupted in type 2 diabetes
}

Jianyang Fu, ${ }^{1}$ John Maringa Githaka, ${ }^{2}$ Xiaoqing Dai, ${ }^{1}$ Gregory Plummer, ${ }^{1}$ Kunimasa Suzuki, ${ }^{1}$ Aliya F. Spigelman, ${ }^{1}$ Austin Bautista, ${ }^{1}$ Ryekjang Kim, ${ }^{1}$ Dafna Greitzer-Antes, ${ }^{3}$ Jocelyn E. Manning Fox, ${ }^{1}$ Herbert Y. Gaisano, ${ }^{3}$ and Patrick E. MacDonald ${ }^{1}$

${ }^{1}$ Alberta Diabetes Institute and Department of Pharmacology and 'Department of Biochemistry, University of Alberta, Edmonton, Alberta, Canada. ${ }^{3}$ Departments of Medicine and Physiology, University of Toronto, Toronto, Ontario, Canada.

Impaired insulin secretion in type 2 diabetes (T2D) is linked to reduced insulin granule docking, disorganization of the exocytotic site, and impaired glucose-dependent facilitation of insulin exocytosis. We show in $\beta$ cells from $\mathbf{8 0}$ human donors that the glucose-dependent amplification of exocytosis is disrupted in T2D. Spatial analyses of granule fusion events, visualized by total internal reflection fluorescence microscopy in $\mathbf{2 4}$ of these donors, demonstrated that these events are nonrandom across the surface of $\beta$ cells from donors with no diabetes. The compartmentalization of events occurs within regions defined by concurrent or recent membrane-resident secretory granules. This organization, and the number of membrane-associated granules, is glucose dependent and notably impaired in T2D $\beta$ cells. Mechanistically, multichannel Kv2.1 clusters contribute to maintaining the density of membrane-resident granules and the number of fusion "hotspots," while SUMOylation sites at the channel N- (K145) and C-terminus (K470) determine the relative proportion of fusion events occurring within these regions. Thus, a glucose-dependent compartmentalization of fusion, regulated in part by a structural role for Kv2.1, is disrupted in $\beta$ cells from donors with T2D.

Conflict of interest: The authors have declared that no conflict of interest exists.

Copyright: (C) 2019, American Society for Clinical Investigation.

Submitted: February 1, 2019 Accepted: May 8, 2019 Published: June 20, 2019

Reference information: /CI Insight. 2019;4(12):e127896. https://doi. org/10.1172/jici.nsight.127896

\section{Introduction}

Insulin, secreted from pancreatic islet $\beta$ cells, is a critical regulator of blood glucose and energy homeostasis in humans (1). Impaired insulin secretion is a hallmark of type 2 diabetes (T2D), which results from a complex interplay between reduced insulin sensitivity and impaired insulin secretion (2). A tipping point occurs when secretion from genetically predisposed $\beta$ cells fails to meet the demands of peripheral insulin resistance $(3,4)$. Although impaired insulin responses in T2D may result from a long-term reduction in $\beta$ cell mass (5), reduced secretory function likely predominates at earlier stages $(6,7)$. In isolated islets or $\beta$ cells from donors with T2D in vitro, exocytotic protein expression is reduced $(8,9)$ and exocytotic responses are impaired $(10,11)$. Most recently this has been attributed to an impaired glucose-dependent granule docking and reduced expression of docking and related active zone proteins (12).

Although $\beta$ cells lack ultrastructurally identifiable active zones, glucose stimulation in situ triggers fusion events that are progressively localized to preferential release sites (13). These appear directed toward the islet vasculature (13-15) and are regulated by extracellular matrix (ECM) interactions with integrin receptors (16), which likely play an important role defining the polarity that defines $\beta$ cell organization in situ (17). Fusion events in vitro also appear nonrandom in insulinoma cells and rodent $\beta$ cells, where exocytosis may occur at sites of recently fused vesicles (18-22). Indeed, syntaxin1A and synaptosomal nerve-associated protein 25 (SNAP-25) cluster at sites of secretory granule docking and exocytosis in single $\beta$ cells $(23,24)$, and reduced SNAP-25 and syntaxin1A clusters correlate with impaired fusion (25). In addition, fusion sites are localized to sites of $\mathrm{Ca}^{2+}$ entry in $\beta$ cells, and this interaction is disrupted in $\beta$ cells from models of T2D $(26,27)$ and $\beta$ cells of human donors with T2D (28). The extent to which fusion events can repetitively occur at defined "hotspots" on the $\beta$ cell membrane, the underlying mechanism for this, and its potential dysregulation in human $\mathrm{T} 2 \mathrm{D}$ remain unclear. 
Among the ion channels that control $\beta$ cell function, the voltage-dependent L-type $\mathrm{Ca}^{2+}$ channels increase intracellular $\mathrm{Ca}^{2+}$ and trigger exocytosis (29). Repolarization of pancreatic $\beta$ cell action potentials is mediated by voltage-dependent $\mathrm{K}^{+}(\mathrm{Kv})$ channels, such as Kv2.1 (30). Interestingly, Kv2.1 also forms multichannel clusters at the plasma membrane (31) that directly facilitate efficient insulin exocytosis (19, 32, 33); may also recruit soluble N-ethylmaleimide-sensitive factor activating protein receptor (SNARE) complex proteins, such as syntaxin1A, SNAP-25, and Munc18-1 (34); and serve as points of contact between the plasma membrane and endoplasmic reticulum (35). The channel regulates exocytosis independently of $\beta$ cell electrical activity by binding syntaxin1A at its C-terminus $(33,36)$, a region that is modified by posttranslational SUMOylation (37). A glucose-regulated deSUMOylation at the plasma membrane appears particularly important for the regulation of insulin secretion (38) and when stimulated can rescue exocytotic responses in human T2D $\beta$ cells (11).

Here we examined exocytotic responses from $\beta$ cells of 80 human donors with and without T2D. We demonstrate an impaired insulin secretion that can occur independently of reduced islet insulin content in this cohort and show an impairment in exocytotic function at the single $\beta$ cell level. By total internal reflection fluorescence (TIRF) microscopy and spatial analyses, we demonstrate a nonrandom distribution of fusion events across the cell membrane and show that this patterning is regulated by glucose and is disrupted in $\beta$ cells of donors with T2D. Knock down of Kv2.1 reduces the spatial organization of these events, and we show that channel clustering controls the density of fusion hotspots while the SUMOylation status of the channel at the $\mathrm{C}$ - and $\mathrm{N}$-terminal sites regulates the overall proportion of fusion events that occur at these sites. Finally, upregulation of Kv2.1 in T2D $\beta$ cells can convert a random distribution of fusion events into a compartmentalized pattern similar to that seen in $\beta$ cells of donors without diabetes.

\section{Results}

Impaired spatial patterning of fusion in $\beta$ cells from donors with T2D. Glucose-stimulated insulin secretion is impaired from islets of donors with T2D $(6,39)$. In a cohort of 80 human islet preparations (Supplemental Tables 1 and 2; supplemental material available online with this article; https://doi.org/10.1172/jci. insight.127896DS1) we show that glucose-stimulated insulin secretion is impaired in T2D and show that this can occur without a reduction in insulin content (Figure 1, A and B). Although we (40) and others (39) have reported reduced islet insulin content from donors with long-standing $\mathrm{T} 2 \mathrm{D}$, the disease duration in these donors is relatively short (average 6.7 years, including some "undiagnosed diabetes"). Donors with longer duration diabetes, or with higher $\mathrm{HbA1c}$, tended to have lower islet insulin content (not shown). In these donors we found that although increasing glucose facilitates exocytosis in $\beta$ cells from donors with no diabetes (ND), seen as a rightward shift in the distribution of exocytotic responsiveness of these cells (Figure 1C), this is impaired in T2D (Figure 1D) consistent with reduced function at the level of single $\beta$ cells (11).

Impaired exocytosis in models of T2D is associated with an uncoupling of exocytosis from sites of $\mathrm{Ca}^{2+}$ entry $(26,27)$, and human T2D $\beta$ cells have a defect in glucose-dependent granule docking (12). We performed live-cell TIRF microscopy of single dissociated $\beta$ cells to assess the spatial relationship of fusion events in cells from a subset of donors with ND and T2D. In this subset, we showed impaired insulin secretory function associated with T2D (Figure 1E). To identify and perform spatiotemporal analysis of vesicle fusion, MATLAB-based software (18) was applied to live-cell recordings obtained over 2 minutes in a bath solution with $5 \mathrm{mM}$ glucose, a concentration shown to facilitate insulin exocytosis (11), following preincubation at $1 \mathrm{mM}$ glucose for 30 minutes. Fusion events from ND $\beta$ cells had a higher degree of spatial organization than those observed in T2D $\beta$ cells, with numerous events appearing to occur repeatedly at hotspots (Figure 1, F-K, and Supplemental Videos 1 and 2) within a defined area of $4 \times 4$ pixels determined by average vesicle diameter (see Methods). Each apparent hotspot was confirmed by generating event heatmaps and comparing relative fluorescence to the first frame (Figure 1, G-J). The spatial organization of events was also confirmed by calculating Ripley's K-function values, which demonstrate a nonrandom distribution of these events (Figure 1, H-K). In ND $\beta$ cells $41.6 \%$ of events occur within spatially localized regions, while only $18.3 \%$ do so in T2D $\beta$ cells.

We confirmed impaired exocytosis by patch-clamp electrophysiology at $5 \mathrm{mM}$ glucose (Figure 2A). From the same donors, live-cell imaging of $\beta$ cells expressing neuropeptide Y-EGFP (NPY-EGFP) to mark secretory granules (Figure $2 \mathrm{~B}$ ) at $5 \mathrm{mM}$ glucose (following a $1 \mathrm{mM}$ glucose preincubation) revealed that accumulated fusion events were decreased $56.1 \%$ in the T2D $\beta$ cells (Figure 2C). Calculation of a clustering index (CI; see Methods) demonstrated that fusion events in the ND $\beta$ cells showed significant compartmentalization ("observed") compared with Monte Carlo simulation run 100 times on each cell, assuming random distribution 

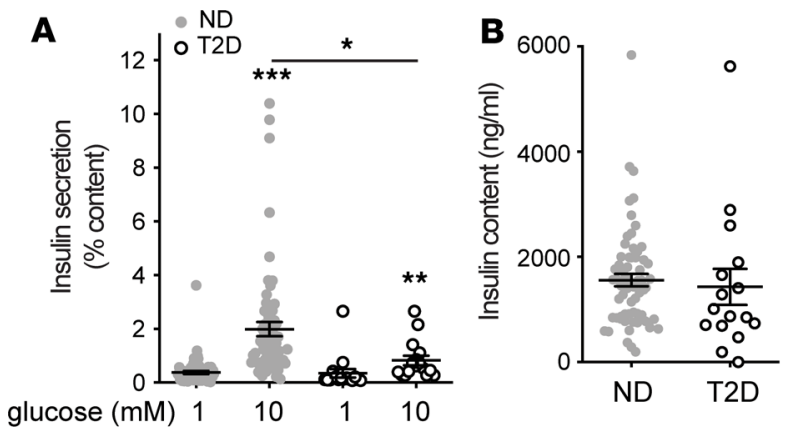
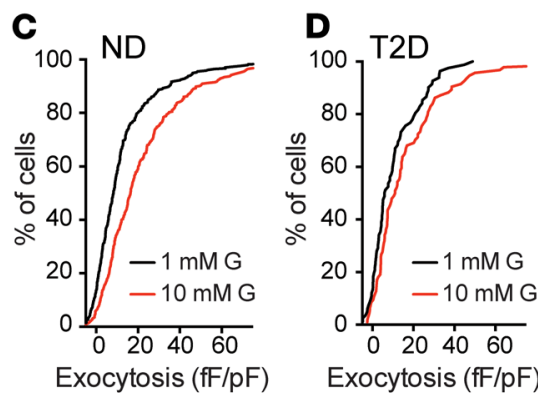

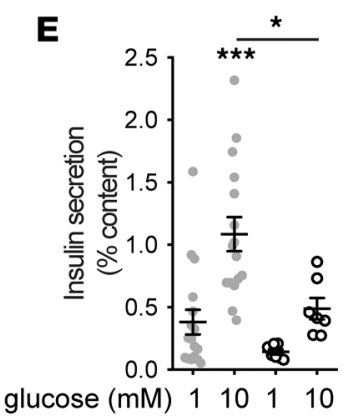

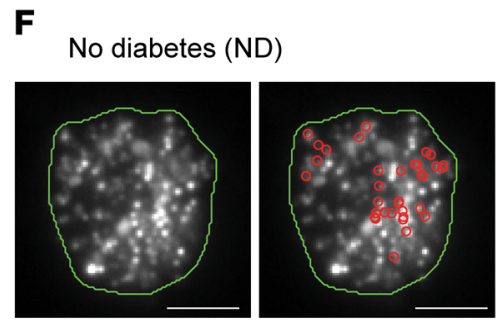

I
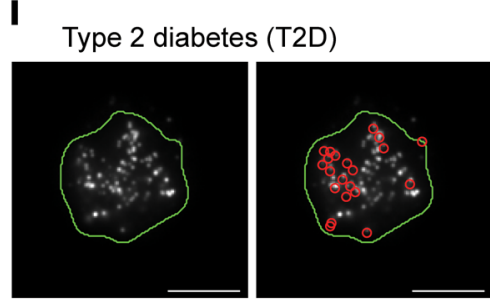
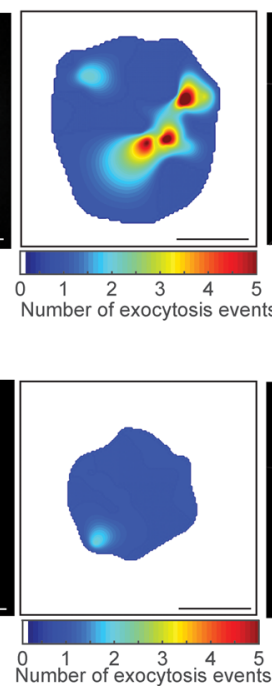

Hotspot 1 Hotspot 2

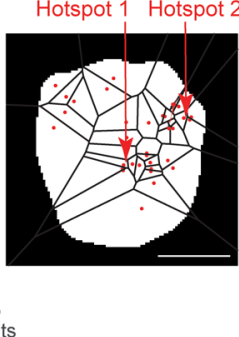

G

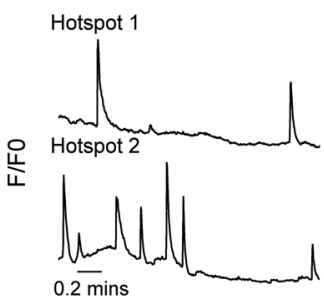

Spot $1 \quad$ Spot 2

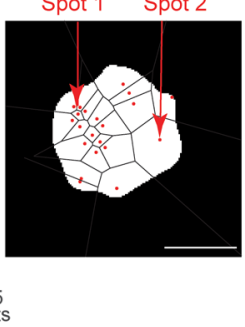

$\mathbf{J}_{\text {Spot } 1}$

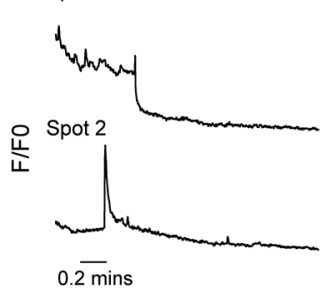

H

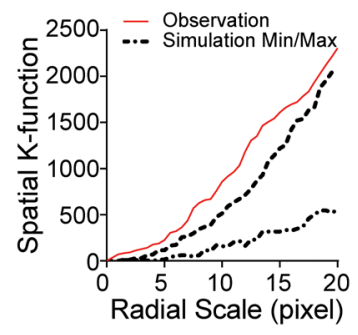

K

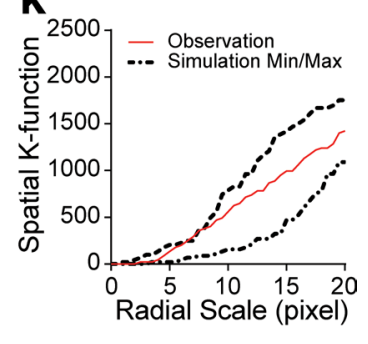

Figure 1. $\beta$ Cell exocytosis is impaired in T2D. (A) Compared with islets of donors with no diabetes (ND; $n=63$ ), glucose-stimulated insulin secretion is impaired from islets of donors with type 2 diabetes (T2D; $n=17$ ). (B) In both sets of donors (average 6.7 years' duration of T2D) islet insulin content is not different. (C and $\mathbf{D}$ ) Cumulative distribution of exocytotic responses of $\beta$ cells from the same donors, measured by patch-clamp electrophysiology. Glucose ( $10 \mathrm{mM}$; red) amplifies the (C) exocytotic responses of ND $\beta$ cells ( $n=701$ cells) (D) but not T2D $\beta$ cells ( $n=156$ cells). (E) Impaired glucose-stimulated insulin secretion observed in the subgroup of ND ( $n=17$ donors) and T2D ( $n=7$ donors) subsequently used for TIRF imaging. (F) In individual $\beta$ cells expressing NPY-EGFP, fusion events (red circles) observed by live-cell TIRF microscopy at 5 mM glucose in ND $\beta$ cells, a heatmap of fusion event density, and Voronoi diagram used to separate exocytosis sites (scale bar: $5 \mu \mathrm{m}$ ). (C) Representative recordings from the areas indicated in $\mathbf{F}$. (H) The nonrandom nature of fusion events in ND $\beta$ cells is demonstrated by spatial K-function calculation (red line) greater than the simulated (dashed lines) maximum. (I-K) The same as F-H but in a T2D $\beta$ cell, where events appear more randomly distributed (scale bar: $5 \mu \mathrm{m}$ ). Significance was determined by (B) Mann-Whitney test or (A and $\mathbf{E}$ ) Kruskal-Wallis 1-way ANOVA followed by Mann-Whitney posttest. ${ }^{*} P<0.05 ;{ }^{* *} P<0.001$.

of events ("simulated"), or events in the T2D $\beta$ cells, which were seen to be no more organized than random simulation (Figure 2D). Although the above analyses account for differences in event frequency, we wished to confirm that the differential organization of events occurs independently of an overall decreased exocytosis, because event frequency correlated with the proportion occurring at hotspots (Figure 2E).

Analysis of a subset of cells with equivalent exocytosis event frequency (Figure 2E, dashed box and inset) demonstrates that the proportion of events occurring at hotspots (Figure $2 \mathrm{~F}$ ) and the density of these (Figure 2G) are decreased in T2D. Thus, impaired insulin secretion from islets of donors with T2D is associated with reduced exocytotic responses, measured both by patch-clamp and live-cell imaging, and with an independent reduction in the compartmentalization of fusion events, determined by generation of exocytotic heatmaps, Ripley's K-function, Voronoi polygon-derived CI, and cell subset analyses.

Glucose-dependent spatial patterning of exocytosis is impaired in T2D $\beta$ cells. In addition to its ability to initiate $\beta$ cell action potential firing, glucose signaling amplifies depolarization-induced insulin secretion and $\beta$ cell exocytosis $(11,41)$. Glucose, but not direct depolarization with $\mathrm{KCl}$, can diminish submembrane granule turnover in mouse $\beta$ cells (42). We stimulated $\beta$ cells with depolarizing $\mathrm{KCl}$ at either 1 or $5 \mathrm{mM}$ glucose. Temporal analysis revealed that exocytosis was impaired in T2D cells under both conditions (Figure 3, A 
A

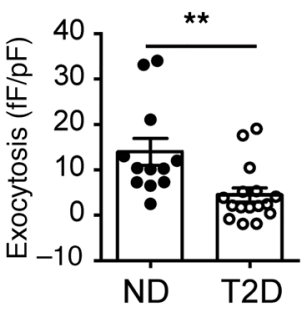

B

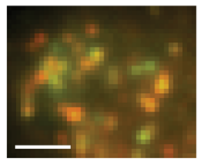

Insulin

NPY-EGFP
C

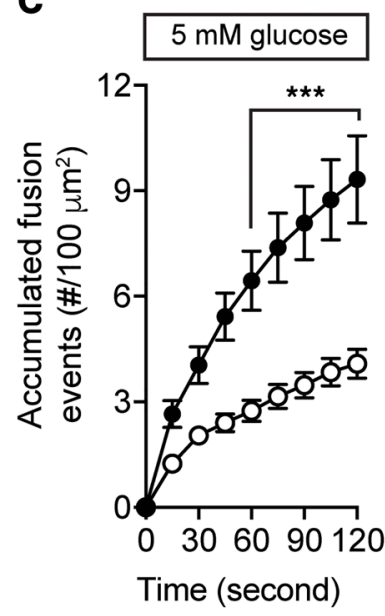

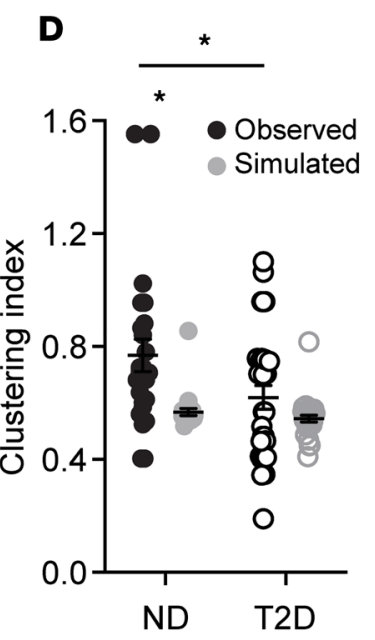
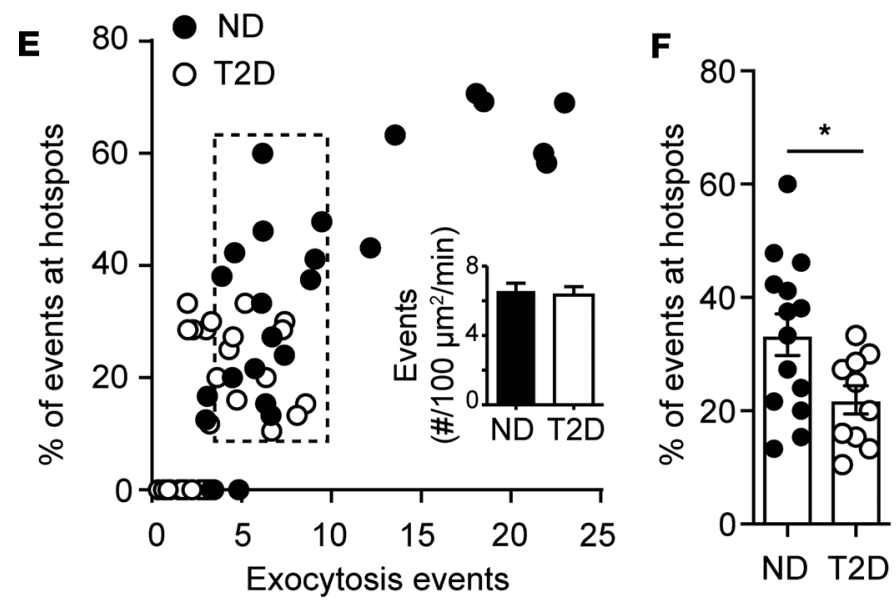

G

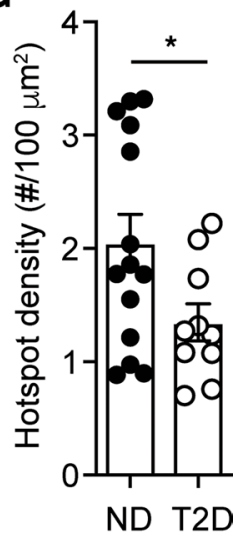

$\left(\# / 100 \mu \mathrm{m}^{2} / \mathrm{min}\right)$

Figure 2. Spatial compartmentalization of granule fusion is reduced in T2D. (A) Exocytosis, measured by patch-clamp in a subset of donors at $5 \mathrm{mM}$ glucose, demonstrates impaired function in T2D ( $n=12$ and 16 cells from $3 \mathrm{ND}$ and 3 T2D donors, respectively). (B and C) In $\beta$ cells expressing NPY-EGFP, which colocalizes with insulin by immunostaining, fusion events were monitored by TIRF microscopy also at $5 \mathrm{mM}$ glucose (ND, black circles, $n=16$ cells from 5 donors; T2D, open circles, $n=26$ cells from 6 donors). Scale bar: $2 \mu \mathrm{m}$. (D) Uniform index of events from C calculated (black) from Voronoi polygon areas and compared with random simulations (gray). (E) Scatter plot of total fusion events versus the proportion that occur within clusters. A subset of cells (dashed box) with equivalent exocytosis (inset) were selected for further analysis. (F) The proportion of events occurring in spatially defined clusters. (C) The density of these clusters. Significance was determined ( $\mathbf{A}$ and $\mathbf{F}$ ) by Student's $t$ test, (C) by ANOVA and Bonferroni's posttest, or (D and $\mathbf{G}$ ) by Kruskal-Wallis 1-way ANOVA followed by Mann-Whitney posttest. ${ }^{*} P<0.05 ;{ }^{* *} P<0.01 ;{ }^{* *} P<0.001$.

and $\mathrm{B})$. At $1 \mathrm{mM}$ glucose, the spatial uniformity of fusion events in ND $\beta$ cells was not different than that predicted by random simulation, but the compartmentalization of events increased in the presence of $5 \mathrm{mM}$ glucose (Figure 3C). When we examined $\beta$ cells with equivalent rates of exocytosis in ND and T2D (Figure 3D, dashed box), $\mathrm{KCl}$-stimulated exocytosis at $5 \mathrm{mM}$ glucose showed an increased proportion of fusion events at hotspots (Figure 3E), along with an increased density of these sites (Figure 3F), effects that are blunted in $\beta$ cells of donors with T2D (Figure 3, E and F).

Observation of fusion occurring near sites of concurrent or recent membrane-resident granules. Insulin granule docking is a critical glucose-dependent step in insulin secretion and is dysregulated in T2D (12). Considering that glucose stimulation recruits and $\mathrm{KCl}$ stimulation depletes docking granules (43), together with our observation that glucose increased the proportion and density of hotspots, we hypothesized that membrane-associated granules may mark sites where repeated exocytosis occurs. Many fusion events throughout our recordings overlapped with sites of membrane-resident granules observed at the initiation of imaging 
A

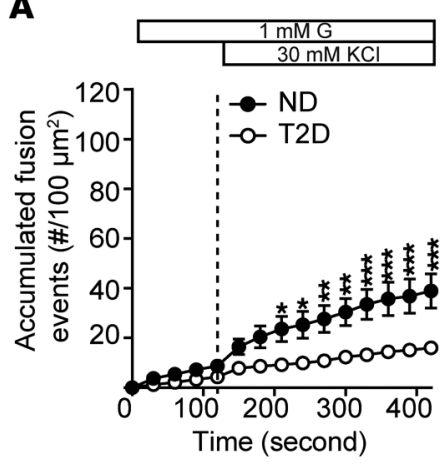

C

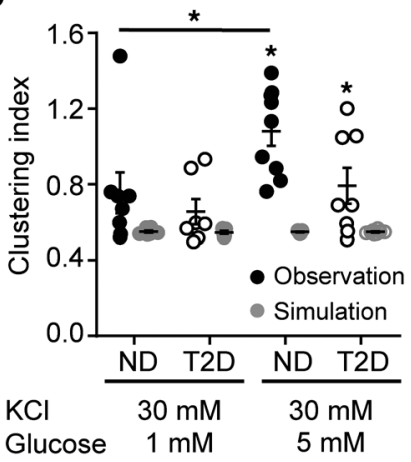

$\mathbf{E}$

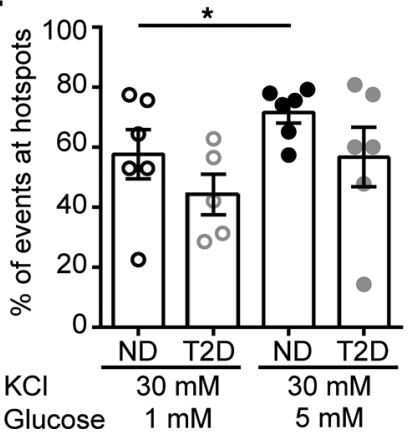

B

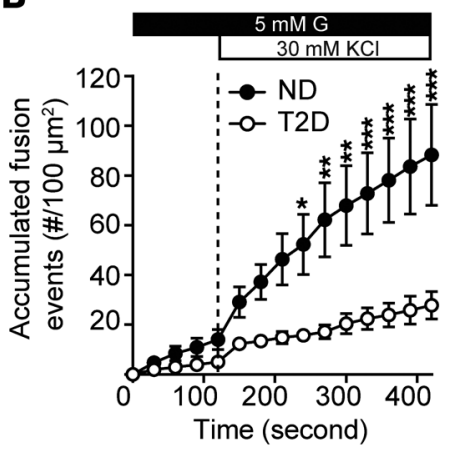

D

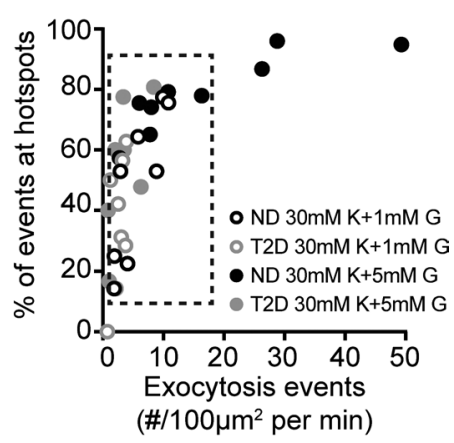

$\mathbf{F}$

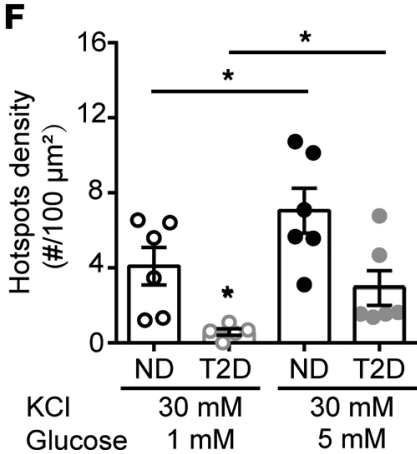

Figure 3. Glucose regulates the spatial organization of fusion events. (A and B) Accumulated fusion events monitored by TIRF microscopy of ND $\beta$ cells (black circles) and T2D $\beta$ cells (open circles) expressing NPY-EGFP, in response to (A) $\mathrm{KCl}$ at $1 \mathrm{mM}$ ( $n=7$ and 8 cells from $6 \mathrm{ND}$ and 3 T2D donors) and (B) $5 \mathrm{mM}$ glucose ( $n=9$ and 9 cells from 6 ND and 3 T2D donors). (C) The uniform index is increased at $5 \mathrm{mM}$ glucose in the ND (closed symbols) but not T2D (open symbols) $\beta$ cells. (D) Scatter plot showing total fusion events versus the proportion of events in spatially restricted clusters. Cells with similar exocytosis (dashed box) used for further analysis. (E) The proportion of events occurring in organized clusters and (F) the density of these clusters are increased at $5 \mathrm{mM}$ glucose in ND $\beta$ cells but impaired in T2D $\beta$ cells. Significance was determined by ANOVA and Bonferroni's posttest. ${ }^{*} P<0.05 ;{ }^{* *} P<0.01 ;{ }^{* *} P<0.001$.

(Supplemental Figure 1 and Supplemental Video 3). As illustrated in Figure 4A and Supplemental Video 4, we observed fusion events that happened both around predocked granules and, later in the same recording, at this site after the predocked granule had fused. We have excluded events from this analysis that occurred within very rapid ( $<1$ second) succession directly overlaid with a docked granule (Figure $4 \mathrm{~B})$ because this may represent "flickering" or "kiss and run" of an individual granule.

Sequential fusion events were less often observed in T2D $\beta$ cells, which were dominated by isolated events (Figure 4C). We found in ND $\beta$ cells (5 mM glucose) that $67.4 \%$ of fusion events occurred at sites marked by membrane-associated granules present within the first frame of the recording, including the fusion of that docked granule itself, while only $55.2 \%$ of exocytosis in T2D cells occurred near such sites (Figure 4D). Importantly, the overall density of membrane-associated granules was decreased $35.8 \%$ in T2D $\beta$ cells (Figure 4D), which is consistent with a previous report (12). 
A
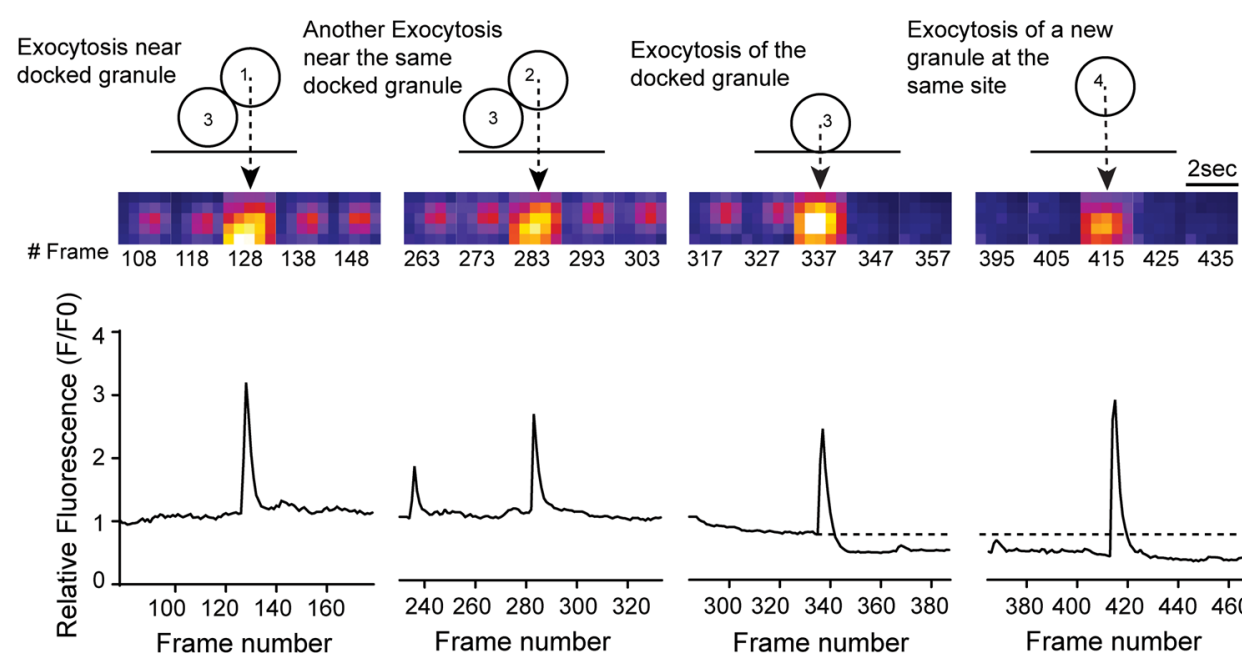

B
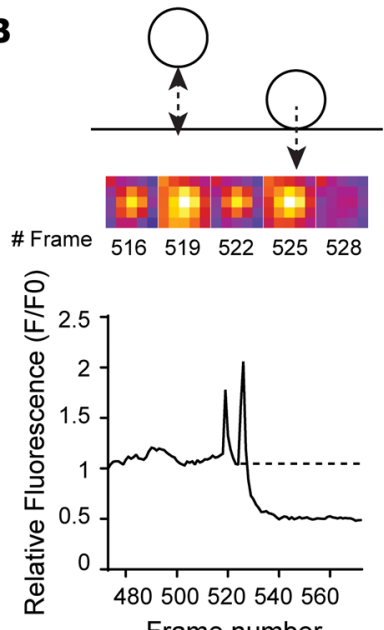

Frame number

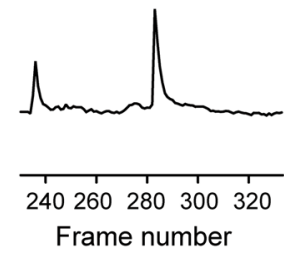

C
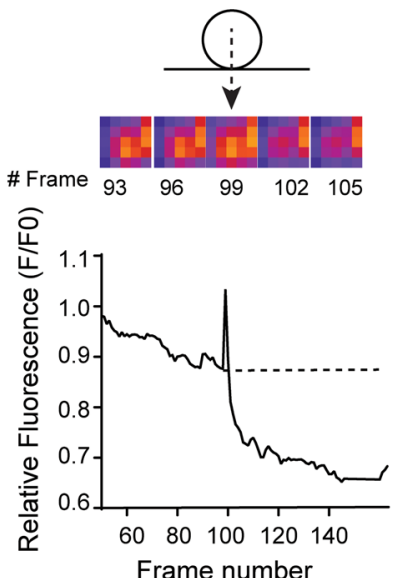
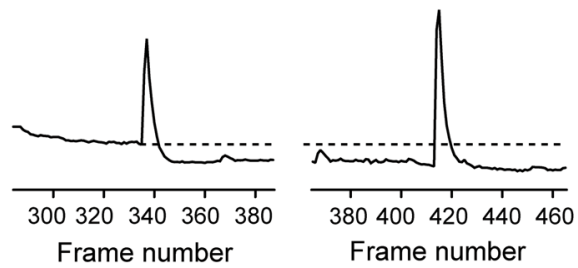

D ND
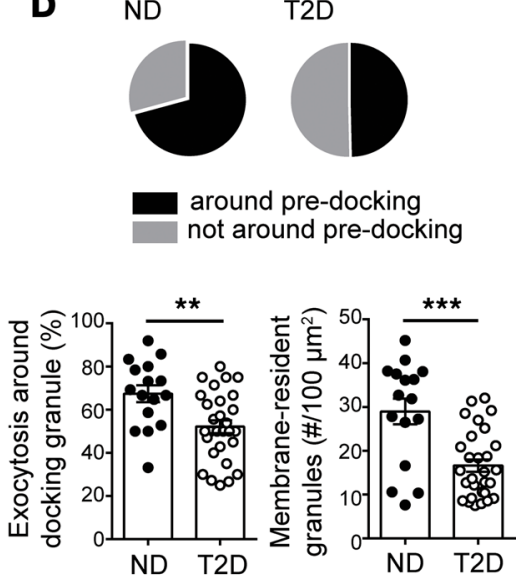

Figure 4. Fusion occurs around sites of concurrent or recent membrane-associated granules. (A) Exocytosis occurring around a membrane-localized granule in an ND $\beta$ cell. Two events occur adjacent to a membrane-resident granule, followed by fusion of that granule itself, and then a new fusion event at the same site. (B) Rapid flickering events before full fusion, illustrated here, are ignored in this analysis. (C) In T2D $\beta$ cells most fusion occurred as individual, rather than as sequential, events. (D) Quantification of the proportion of events occurring around initially membrane-localized granules (pie charts and bottom left) and the initial density of membrane-resident granules (bottom right; $n=16$ and 28 cells from 3 ND and 3 T2D donors, respectively). Significance was determined by Student's $t$ test. ${ }^{* *} P<0.01 ;{ }^{* *} P<0.001$.

The density of membrane-resident granules and fusion hotspots is controlled by Kv2.1. We demonstrated previously in insulinoma cells that the formation of multichannel clusters of Kv2.1 controls the density of membrane-associated granules (32) and that fusion events occur on the periphery of Kv2.1 clusters (19). Knock down of Kv2.1 expression in human $\beta$ cells (Figure 5A) reduced the density of predocked secretory granules (Figure 5B) and the frequency of fusion events observed at $5 \mathrm{mM}$ glucose (following a $1 \mathrm{mM}$ glucose preincubation; Figure $5 \mathrm{C}$ ) but not the overall proportion of those events that occurred near the predocked granules (Figure 5D). The compartmentalization of fusion events, determined by calculation of CI, was not significantly reduced following Kv2.1 knock down (Figure 5E). Similar results were observed upon analysis of a subset of cells (Figure 5F, dashed box) with similar levels of exocytosis (Figure 5G), where the proportion of exocytotic events occurring at hotspots was unchanged (Figure $5 \mathrm{H}$ ), but the overall density of these hotspots was decreased (Figure 5I).

The formation of multichannel clusters is required for the facilitation of $\beta$ cell exocytosis by Kv2.1 (19, 32). Expression of a $\mathrm{C}$-terminal-truncated channel (Kv2.1- $\Delta \mathrm{C} 318)$ shown by us and others to be clustering deficient $(32,44)$ in ND $\beta$ cells reduced the compartmentalization of fusion events (Figure 6A). In a subset of ND cells with equivalent exocytosis (Figure 6B, dashed box), upregulation of WT Kv2.1 did not affect 
A

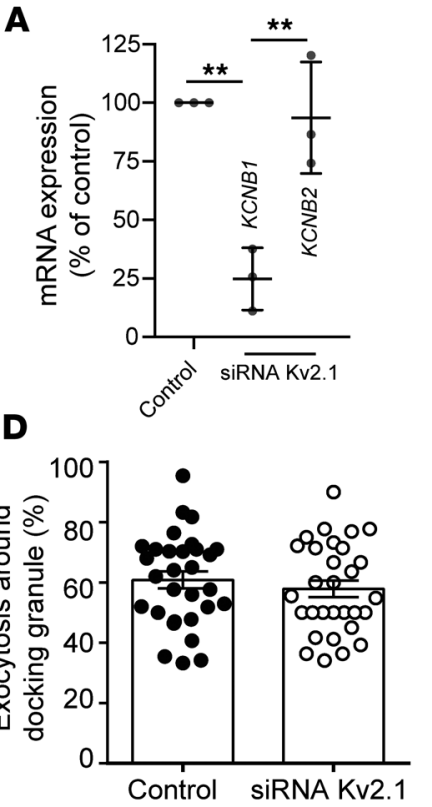

G

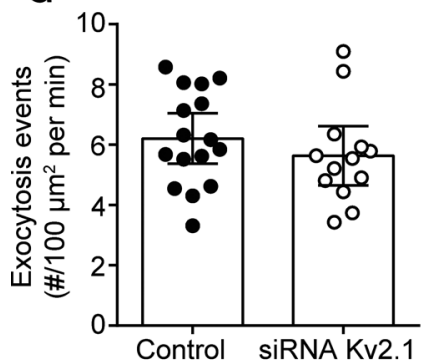

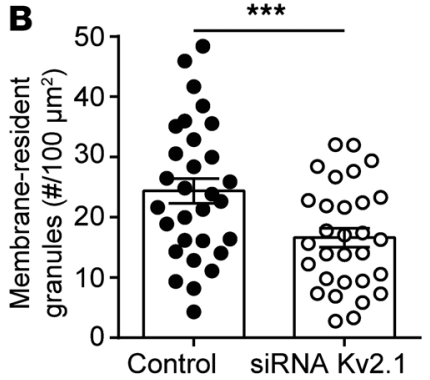

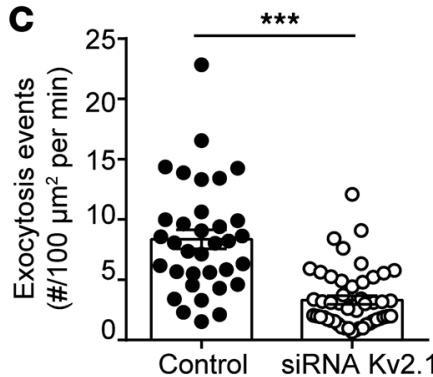

E

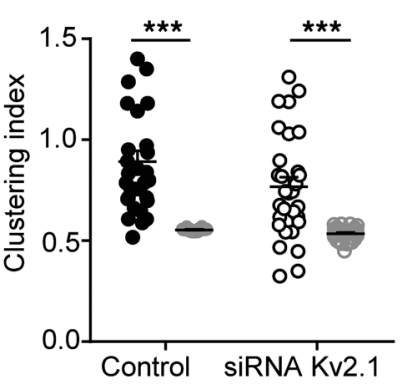

$\mathbf{F}$

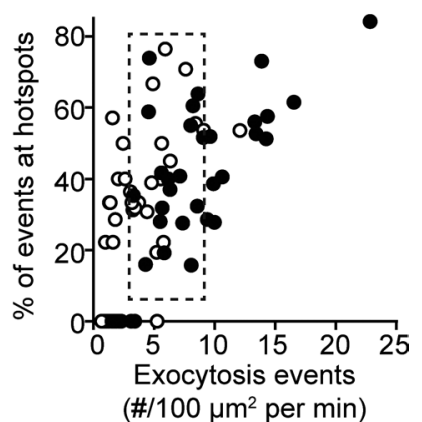

H

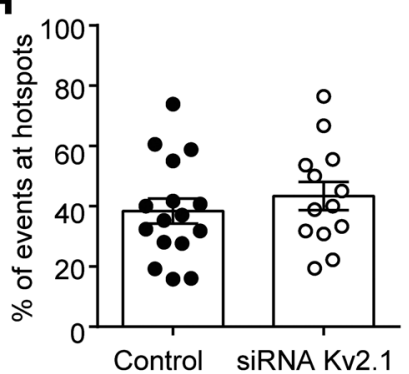

I

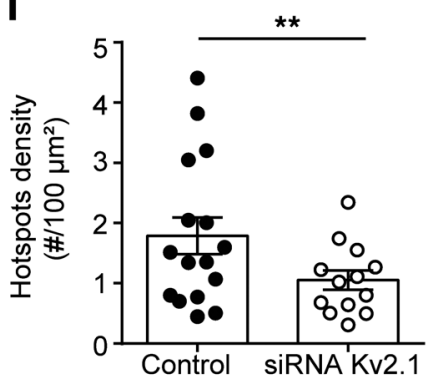

Figure 5. Kv2.1 regulates the density of membrane-resident granules and clustered fusion sites. (A) Knock down of Kv2.1 expression by siRNA in human islet cells confirmed by quantitative PCR of Kv2.1 (KCNB1) and the related Kv2.2 (KCNB2). (B) The initial density of membrane-resident granules marked by NPY-EGFP is reduced by Kv2.1 knock down, as is (C) the frequency of exocytotic events. (D) This occurs without a change in the overall proportion of fusion events occurring at sites marked by membrane-resident granules ( $n=30$ and 30 cells from 3 donors). (E) The spatial organization of these events is only modestly decreased. (F) Examination of a subset of cells (dashed box) (C) with similar event frequency $(\mathbf{H})$ demonstrates that the proportion of events occurring in spatially clustered regions is unchanged by Kv2.1 knock down (I) while the density of these sites is decreased. Significance was determined by (A) ANOVA and Bonferroni's posttest, (B-D and G-I) by Student's $t$ test, or (E) by Kruskal-Wallis 1-way ANOVA followed by Mann-Whitney posttest. ${ }^{* *} P<0.01 ;{ }^{* *} P<0.005$.

the spatial organization of fusion events, while Kv2.1- $\Delta \mathrm{C} 318$ decreased the proportion of events occurring at hotspots in ND $\beta$ cells (Figure 6C) without affecting the overall hotspot density compared with cells expressing mCherry alone (Figure 6D). In T2D $\beta$ cells, upregulation of the WT channel restored the spatial compartmentalization of events (Figure 6, E-H). We found that upregulation of "clustering-sufficient" WT Kv2.1 increased membrane-resident secretory granules by $30.0 \%$ and increased exocytosis at these sites by $42.4 \%$ compared with the mCherry control group in ND donors (Supplemental Figure 2A). Similarly, in T2D donors the WT Kv2.1, but not the "clustering-deficient" Kv2.1- $\Delta \mathrm{C} 318$, increased membrane-associated granules by $37.5 \%$ and increased fusion events around them by $50 \%$ (Supplemental Figure $2 \mathrm{~B}$ ).

SUMOylation sites on Kv2.1 determine the proportion of fusion events occurring in hotspots. The clustering of Kv2.1 contributes to the spatial coordination of fusion events secondary to the control of membrane-resident granule density. We (45) and others (37) have shown that Kv2.1 is regulated by posttranslational SUMOylation, which has also been shown to negatively regulate insulin exocytosis (38). The most well-established SUMOylation site on the channel is located at lysine 470 (37) within a syntaxin1A-binding domain of the C-terminus (46) previously shown to have a role in $\beta$ cell exocytosis (33). A second SUMOylation motif, 
ND

A

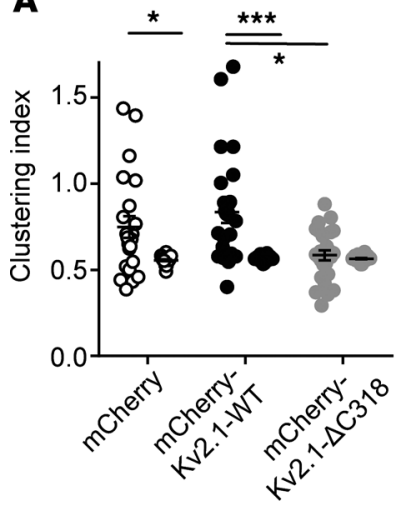

T2D

E

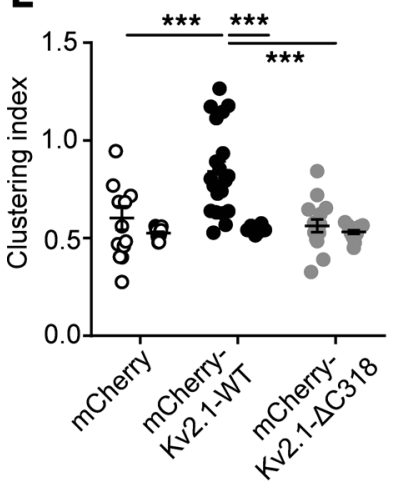

B

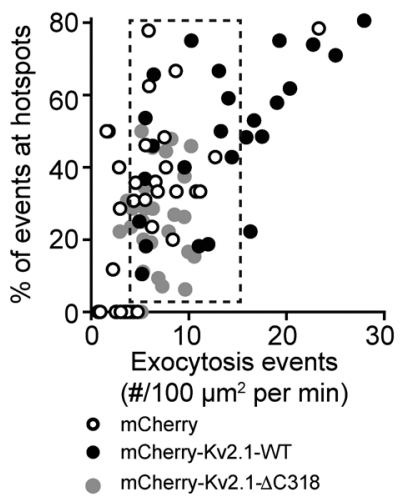

F

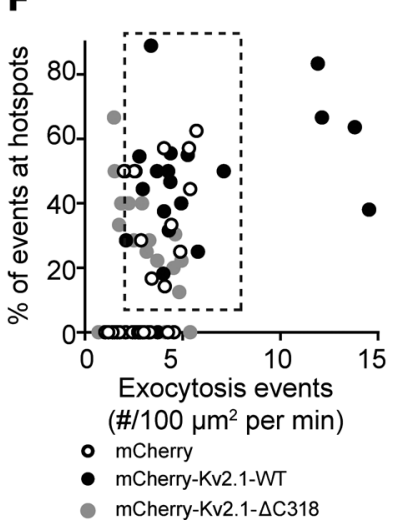

C

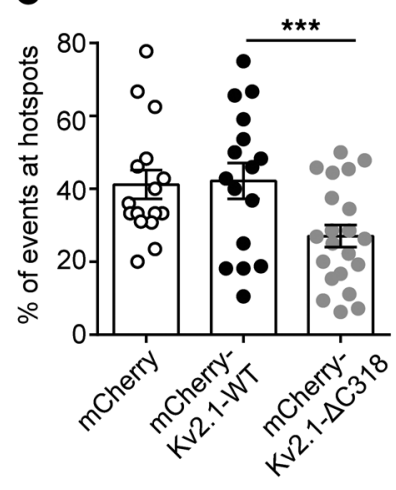

G

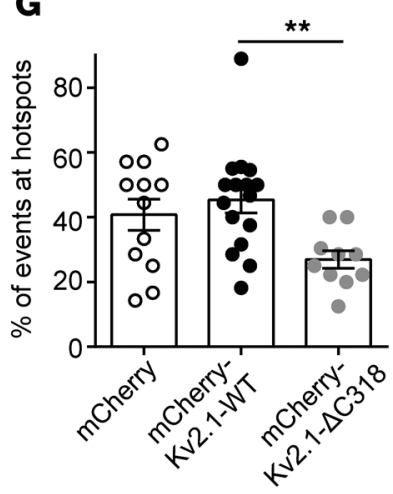

D

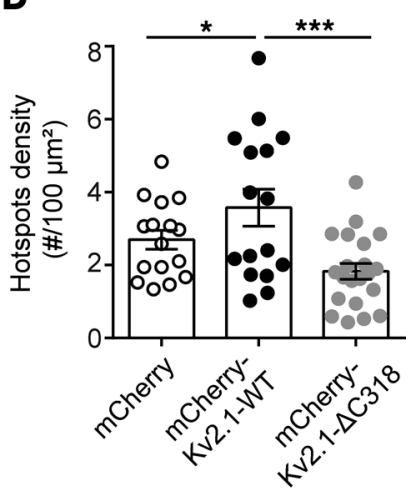

H

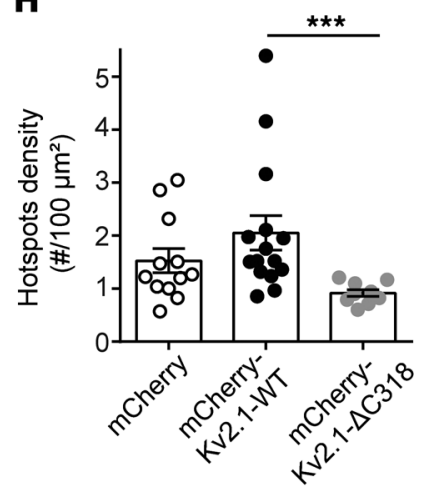

Figure 6. Upregulation of Kv2.1 restores the spatial organization of fusion sites in T2D $\beta$ cells. (A) In ND $\beta$ cells, compared with the full-length channel (Kv2.1-WT), a clustering-deficient mutant (KV2.1- $\triangle$ C318) reduced the uniformity of fusion events monitored by TIRF imaging of granule-targeted NPY-EGFP ( $n=22,26$, and 24 cells from 3 donors). Cells expressing the channel constructs were identified by channel-tagged mCherry and compared to cells expressing mCherry alone. (B) In a subset of cells with equivalent rates of exocytosis (dashed box), (C) expression of Kv2.1-WT had little effect on the proportion of events within hotspots and (D) slightly increased their density, while Kv2.1- $\Delta$ C318 reduced the overall contribution of hotspots to exocytosis. (E-H) Same as A-D, but in T2D $\beta$ cells ( $n=12,16$, and 10 cells from 3 donors). Here, Kv2.1-WT rescued the compartmentalization of fusion events. (F) In a subset of cells with similar fusion frequency (dashed box), (C) the overall proportion of events occurring in these spatially restricted regions and (H) the density of these sites are unchanged by WT-Kv2.1. Significance was determined by Kruskal-Wallis 1-way ANOVA followed by (A and $\mathbf{H}$ ) Mann-Whitney posttest or by (C-E and G) ANOVA and Bonferroni's posttest. ${ }^{*} P<0.05$; ${ }^{* *} P<0.01$; ${ }^{* *} P<0.001$.

at lysine 145 within a potential SNAP-25-binding domain in the N-terminus (47), is more highly conserved across species (Supplemental Figure 3A) and homologous to a demonstrated SUMOylation site in other Kv channels, such as Kv1.1, Kv1.2, and Kv1.5 (ref. 48 and Supplemental Figure 3B). Mutation of K145 does not appear to alter Kv2.1-mediated $\mathrm{K}^{+}$currents (37), which we demonstrate (Figure 7, A and B). However, loss of the K145 SUMOylation site (Kv2.1-K145R) blunted the suppressive effect of SUMO1 on exocytosis in insulinoma cells (Figure 7, C-F) and when combined with abolishing the K470 SUMOylation site (Kv2.1K145/470R) completely prevented SUMO1-dependent suppression of exocytosis (Figure 7F).

In human $\beta$ cells from donors without diabetes, increasing SUMO1 reduced the compartmentalization of fusion events (Figure 8, A and B). Loss of Kv2.1 SUMOylation sites in the Kv2.1-K145/470R double mutant prevented compartmentalization (Figure 8, C and D). We found that SUMO1 reduced the compartmentalization of events such that the $\mathrm{CI}$ was no longer different from random simulations, and compartmentalization was completely prevented in the Kv2.1-K145/470R group (Figure 8E). Finally, in cells with equivalent rates of exocytosis (Figure $8 \mathrm{~F}$, dashed box), SUMOylation of Kv2.1 reduced the proportion of fusion events occurring within hotspots (Figure 8G) with only minimal effect on total hotspot density (Figure 8H). Altogether, we found that multichannel Kv2.1 clusters promoted the recruitment of membrane-resident secretory granules, which define sites of compartmentalized fusion. The actual targeting of granules to these sites depended on deSUMOylation of the channel (Supplemental Figure 4). 
A

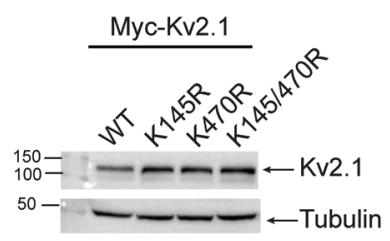

C

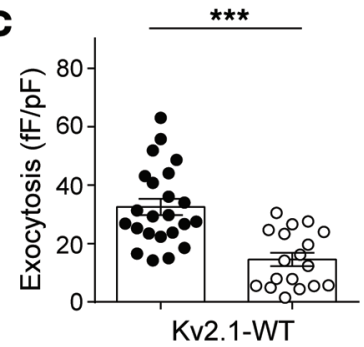

SUMO-1 - +

E

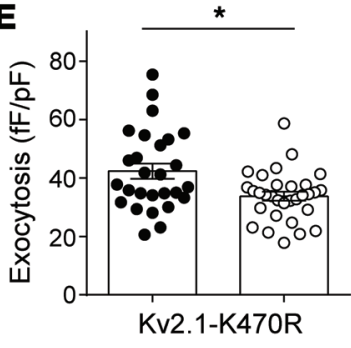

SUMO-1 -
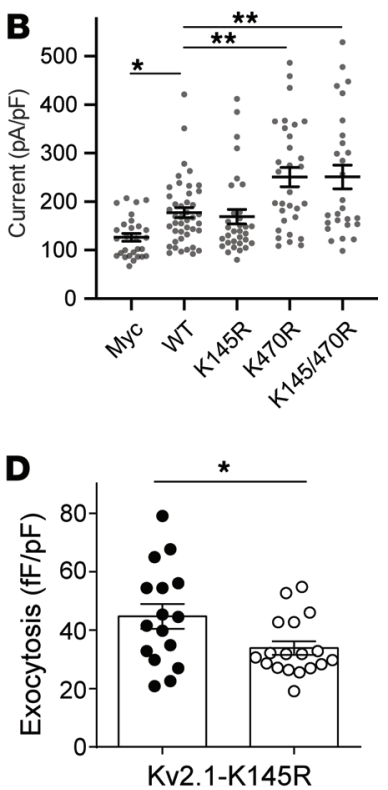

SUMO-1 - +

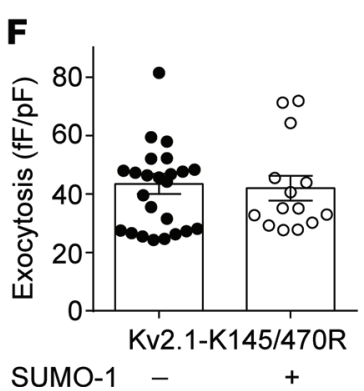

Figure 7. SUMOylation sites on the Kv2.1 $\mathbf{N}$ - and C-termini control $\beta$ cell exocytosis. (A) When expressed in human embryonic kidney 293 (HEK293) cells, mutation of Kv2.1 C-terminal (K470R) or N-terminal (K145R) SUMOylation sites, alone or in combination, has no effect on channel protein level (representative of 3 experiments). (B) When expressed in INS $832 / 13$, cells' loss of the K145 site has no effect on channel current measured by whole-cell patch-clamp electrophysiology, while currents are increased upon mutation of $\mathrm{K} 470$ or of both sites in concert ( $n=16,20,27,20$, and 28 cells). (C-F) When examined by measurement of cell capacitance responses, SUM01 suppresses exocytosis in INS 832/13 (C) cells expressing Kv2.1-WT ( $n$ $=23,18$ cells), and this effect is reduced in (D) cells expressing Kv2.1-K145R ( $n=16,18$ cells) or (E) cells expressing Kv2.1-K470R ( $n=$ 27, 29 cells). (F) Mutation of both SUMOylation sites (Kv2.1-K145/470R; $n=24,14$ cells) abolished the inhibitory effect of SUMO1 on exocytosis. Significance was determined by (B) Kruskal-Wallis 1-way ANOVA followed by Mann-Whitney posttest, by (C and $\mathbf{E}$ ) nonparametric Mann-Whitney test alone, or (D and $\mathbf{F}$ ) by Student's $t$ test. ${ }^{*} P<0.05 ;{ }^{* *} P<$ 0.01 ; and ${ }^{* *} P<0.001$.

\section{Discussion}

The regulated exocytosis of insulin from human pancreatic $\beta$ cells is impaired in T2D. Indeed, reduced exocytotic function is observed even in $\beta$ cells of nondiabetic human donors with genetic risk for T2D (10). Several factors likely contribute to this lower exocytotic responsiveness, including reduced SNARE expression (8), a loss of regulatory metabolic signals (11), impaired microtubule (49) or actin (50) regulation of granule access to the membrane, and the uncoupling of granule fusion from sites of $\mathrm{Ca}^{2+}$ entry. The latter has been described in models of free fatty acid culture (26), in high fat diet-fed mice (27), and in $\beta$ cells from human T2D donors (28). Recently, the glucose-dependent recruitment of granules to docking sites was shown to be a limiting step in insulin secretion, which is disturbed in T2D (12). The spatial organization of events at the plasma membrane, such as the localization of integrin signals (16) or the clustering of $\mathrm{Ca}^{2+}$ channels (28), is an important determinant of regulated insulin secretion. However, little is understood about the control of the spatial patterning of fusion events in human health and T2D.

An insulin secretory deficit, including a reduced responsiveness to glucose, is an important determinant of T2D development and progression (51). Although impaired islet mass may contribute to reduced insulin secretion in $\mathrm{T} 2 \mathrm{D}$, at least later in the disease (5), the contribution of reduced islet insulin content versus impaired secretory responses early in T2D progression is less well recognized. Although insulin content has been shown to be decreased in T2D human islets by us (40) and others (39), in the present data set we observed impaired insulin secretory responses without an obvious decrease in insulin content. This is likely due to the relatively short duration of $\mathrm{T} 2 \mathrm{D}$ in this cohort (6.7 \pm 1.9 years), where only 5 of 17 donors had reported disease duration of 10 years or more. Of the T2D donors with no information on disease duration, one's diabetes appeared well controlled (HbA1c 6.2), and the other case was managed with diet only. One additional diet-controlled T2D donor (R198) diagnosed 10 years prior may be considered in remission based on available information (see Methods). Although this donor-to-donor heterogeneity could complicate the interpretation 
A

\section{Kv2.1-WT}
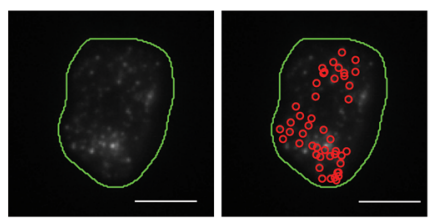

C Kv2.1-K145/470R
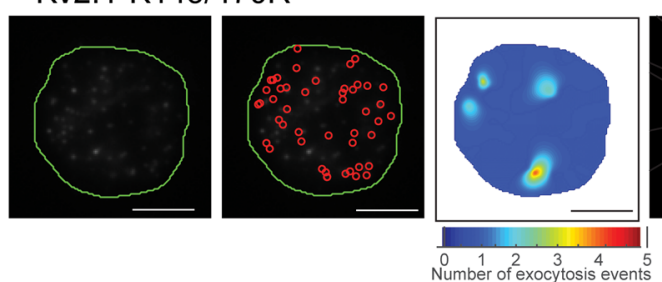

$\mathbf{F}$

E

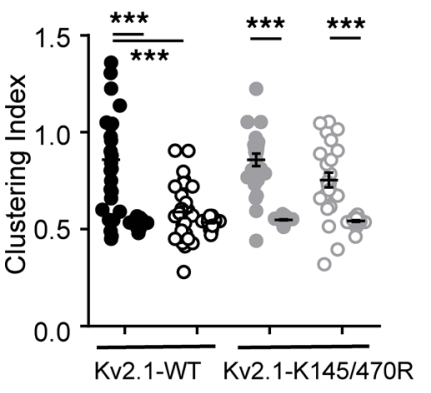

SUMO-1 - + - +

- Kv2.1-WT

- Kv2.1+SUMO-1

- Kv2.1-K145/470R

- Kv2.1-K145/470R+SUMO-1

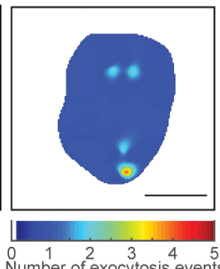

B

Kv2.1-WT+SUMO-1
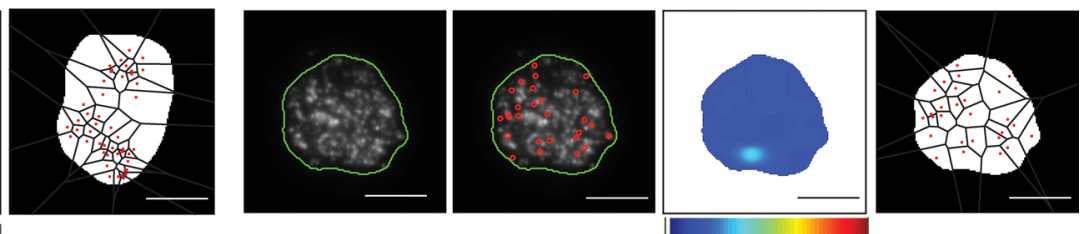

Number of exocytosis events

D

Kv2.1-K145/470R+SUMO-1
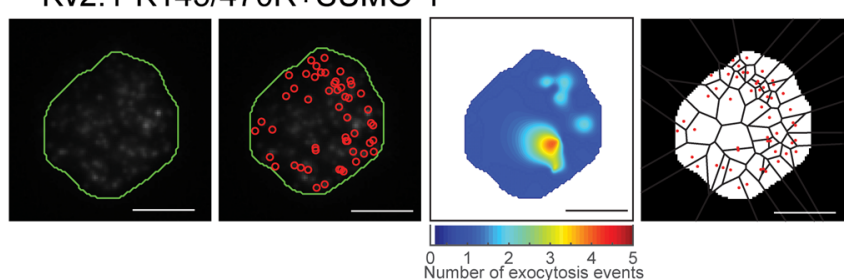

H
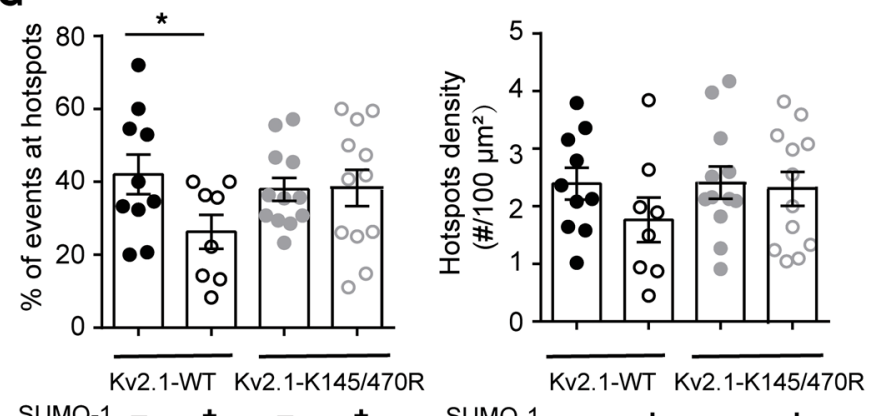

Figure 8. Kv2.1 SUMOylation sites regulate compartmentalization of fusion events. (A-D) Example fusion events tracked by TIRF imaging of NPY-EGFP expression shown individually (red circles), as density heatmaps, or separated by Voronoi polygons in ND $\beta$ cells expressing KV2.1-WT (A) alone or (B) with SUM01 and KV2.1-K145/470R (C) alone or (D) with SUM01. Scale bars: $5 \mu \mathrm{m}$. (E) Uniformity index values calculated from Voronoi polygons show that SUM01 reduces the compartmentalization of fusion events in cells expressing Kv2.1-WT but not the SUMOylation-deficient mutant Kv2.1-K145/470R ( $n=10,8,12$, and 12 cells from 4 donors). (F) Scatter plot showing the relationship between proportion of events occurring within hotspots versus event frequency. A subset of cells (dashed box) was chosen for further analysis. (G and $\mathbf{H})$ SUMO1 reduced the proportion of events occurring at (G) hotspots with little effect on $(\mathbf{H})$ the overall hotspot density. Significance was determined by ANOVA followed by Bonferroni's posttest. ${ }^{*} P<0.05 ;{ }^{* * *} P<0.001$.

of secretion results, which is the case for all human islet studies, in this paper we have taken a step forward in addressing this by linking each preparation used to its full donor, quality control, and islet function data via a Web tool (http://www.isletcore.ca) and hyperlinks provided in Supplemental Tables 1 and 2.

Single-cell impairments in insulin exocytosis from human T2D $\beta$ cells $(11,32)$ may result from reduced glucose-dependent granule docking (12) and disrupted localization of granule fusion to sites of $\mathrm{Ca}^{2+}$ entry (26-28). Previous studies have suggested both directional control of insulin release toward the vasculature in situ (13-15) and the existence of repetitive release sites (18-22). Focal adhesion activation may contribute to this (52), resulting from ECM-dependent interactions that drive cell polarity in situ (17). Although it seems likely that the additional signals, such as integrin activation by the ECM interactions (16), would provide an additional layer of organization, we observed a glucose-dependent spatial patterning of fusion events across the surface of isolated $\beta$ cells that were defined by the presence of previously or concurrently docked granules. The observation that membrane-docked granules mark hotspots in $\beta$ cells suggests that the reduced organization of fusion events in T2D $\beta$ cells could be secondary to impaired glucose-dependent granule docking. In T2D donors reduced glucose-dependent docking is suggested as a major upstream defect (12), and we also report a reduced density of membrane-associated granules in T2D cells. 
SNARE proteins and ion channels are compartmentalized across the cell membrane in complexes that are generally thought to facilitate efficient exocytosis. Previously, we reported that Kv2.1 in pancreatic $\beta$ cells colocalizes with docking granules $(19,32)$ and directly facilitates exocytosis independent of its electrical function (36) in a manner that is dependent upon the formation of multichannel clusters (32). Indeed, we recently demonstrated that fusion events in insulinoma cells occur adjacent to Kv2.1 clusters (19) and suggested that these sites act as "reservoirs" for the provision of release-competent granules. This role is supported by our observation that depletion or overexpression of Kv2.1 reduces or increases, respectively, the density of membrane-resident granules and, consequently, the density of fusion hotspots (Supplemental Figure 4). These manipulations have little or no effect on the overall proportion of total fusion events occurring within these hotspots, suggesting that although clustered Kv2.1 channels contribute to setting the number of hotspots, another mechanism is involved in directing fusion to these sites.

SUMOylation is an important regulatory mechanism for membrane proteins. Kv2.1 can be SUMOylated $(37,45)$, and we found an important functional effect of manipulating SUMOylation sites in both the N-terminus and the C-terminus of the channel. The N-terminal SUMOylation site is less well established and has no apparent effect on the biophysical function of $\mathrm{K}^{+}$conductance, in line with a previous report (37). We did, however, find that this site was more highly conserved between species and among $\mathrm{Kv}$ isoforms. This site in Kv1.5 has a demonstrated function in SUMO control of the channel (48), and here we show that mutation of the consensus lysine residue (K145) reduced the inhibitory effect of SUMOylation on exocytosis in concert with the C-terminal site (K470). This had only minimal effect on the density of hotspots but instead controlled the occurrence of fusion at these sites (Supplemental Figure 4). It seems that Kv2.1 SUMOylation, which occurs at sites of syntaxin1A/-3 (53) and SNAP-25 (47) binding, might not alter the ability of granules to be recruited to the "reservoir," but instead affect the transfer of granules to the fusion sites. This, and the roles in sequential insulin granule fusion for Munc18b (20) and syntaxin3 (54), which bind the channel (19), suggest that the likely mechanism for the sequential fusion at hotspots involves Kv2.1 interactions with an alternative SNARE complex.

In summary, we demonstrate a glucose-dependent spatiotemporal compartmentalization of insulin granule fusion events in human $\beta$ cells. This contributes to the amplification of insulin exocytosis by glucose and is perturbed in T2D. The voltage-gated $\mathrm{K}^{+}$channel Kv2.1 plays a structural role in this process, possibly as a component of a complex serving as a "reservoir" of granules for future fusion. Multichannel clusters of Kv2.1 set the density of these "hotspot platforms," while deSUMOylation of the channel determines the progression of insulin granules to fusion competence at these sites.

\section{Methods}

Human islets and cell culture. Human islets were isolated at the Alberta Diabetes Institute IsletCore according to procedures deposited in the protocols.io repository (55). A total of 63 donors with ND (Supplemental Table 1) and 17 donors with T2D (Supplemental Table 2) were examined in this study. Extended donor, organ processing, and quality control information is available via hyperlinks for each donor in the Supplemental Tables or by searching relevant donor numbers at http://www.isletcore.ca. The presence of T2D was determined by clinical reporting at the time of organ procurement or an $\mathrm{HbA1c}$ greater than $6.5 \%$ measured from blood tubes provided with the shipped organ. Before experiments, islets were cultured in low-glucose (5.5 mM) DMEM with L-glutamine, $110 \mathrm{mg} / \mathrm{L}$ sodium pyruvate, 10\% FBS, and $100 \mathrm{U} / \mathrm{mL}$ penicillin/streptomycin. One donor (R198), with a prior T2D diagnosis, appears to have been in remission with diet-based management but was retained in the T2D group because islet phenotyping demonstrated impaired insulin secretion and $\beta$ cell exocytosis.

HEK293 cells from ATCC were cultured in DMEM with $20 \mathrm{mM}$ glucose, 10\% FBS, 100 units/ $\mathrm{mL}$ penicillin, and $100 \mathrm{mg} / \mathrm{mL}$ streptomycin at $37^{\circ} \mathrm{C}$ and $5 \% \mathrm{CO}_{2}$. The glucose-responsive INS $832 / 13$ insulinoma cell line (56) from Christopher Newgard (Duke University, Durham, North Carolina, USA) was cultured in RPMI 1640 (Life Technologies/Thermo Fisher Scientific) with $11.1 \mathrm{mM}$ glucose, 10\% FBS, $10 \mathrm{mM}$ HEPES, $0.29 \mathrm{mg} / \mathrm{ml}$ L-glutamine, $1 \mathrm{mM}$ sodium pyruvate, $50 \mu \mathrm{M} 2$-mercaptoethanol, 100 $\mathrm{U} / \mathrm{mL}$ penicillin, and $100 \mathrm{mg} / \mathrm{mL}$ streptomycin.

Adenoviruses, constructs, and treatments. Human pancreatic islets were dissociated using Cell Dissociation Buffer, enzyme-free, Hanks' Balanced Salt Solution (Thermo Fisher Scientific). Isolated human pancreatic $\beta$ cells were infected with adenovirus expressing NPY-EGFP and further cultured for 24-36 hours before imaging. We confirmed the localization of NPY-EGFP to insulin granules by immunostaining. Adeno-NPY-EGFP-infected human pancreatic $\beta$ cells were transfected for 36-48 hours with the expression plasmids as outlined for each experiment using Lipofectamine 2000 (Life Technologies). 
The cDNA-encoding WT rat Kv2.1 or the truncated Kv2.1- $\Delta$ C318 (Kv2.1 Glu536_Ile853 del) was amplified by PCR, using a pcDNA3.1-Kv2.1 plasmid (45) as a template, and inserted between the BsrG-I and Xho-I site of Cherry-LacRep plasmid (from Mirek Dundr, Rosalind Franklin University of Medicine and Science, North Chicago, Illinois, USA; Addgene plasmid 18985) by Gibson Assembly to make mCherry-Kv2.1-WT and mCherry-Kv2.1- $\Delta$ C318.

To generate Myc-tagged Kv2.1 plasmids, the cDNA-encoding 5xMyc was inserted between the Nhe-I and BsrG-I sites of the mCherry-Kv2.1-WT and mCherry-Kv2.1- $\Delta$ C318 expression vector by Gibson Assembly. To generate the mutation of SUMOylation sites in Kv2.1, site-directed mutagenesis was performed in a Myc-tagged Kv2.1-WT expression vector to introduce the mutation from lysine to arginine at positions K145, K470, and K145/470. All mutations were confirmed by Sanger DNA sequencing, and expression was confirmed by Western blotting with anti-Myc primary antibody (1:2000 dilution; MilliporeSigma 06-340).

The full-size human SUMO1 cDNA, internal ribosome entry site (IRES) DNA, and mCherry cDNA were prepared by PCR using pEYFP SUMO-1 plasmid (from Mary Dasso, National Institutes of Health, Bethesda, Maryland, USA; Addgene plasmid 13380), pWPI plasmid (from Didier Trono, Swiss Federal Institute of Technology, Lausanne, Switzerland; Addgene plasmid 12254), or Cherry-LacRep plasmid as templates, respectively. The pCMV-hSUMO1-IRES-mCherry plasmid was constructed by inserting the cDNA/ DNA of human SUMO1, IRES, and mCherry, in this sequence, between the Nhe-I and BamH-I sites of the Cherry-LacRep plasmid by Gibson Assembly. A negative control plasmid, pIRES-mCherry, was prepared in the same manner but without human SUMO1 cDNA.

Finally, knock down of KCNB1 expression in human cells was carried out using a mixture of 4 siRNA duplexes (Qiagen, catalog S100070777, S100070791, S100070798, and S103065930) in which each recognizes different regions of the human KCNB1 gene. Knock down of KCNB1 was confirmed by quantitative PCR using TaqMan expression assays (assay ID Hs00270657_m1 for KCNB1 and Hs00191116_m1 for KCNB2, Applied Biosystems, Thermo Fisher Scientific).

Insulin secretion and electrophysiology. The insulin secretion measurements are detailed in the protocol deposited to protocols.io (57). Glucose concentrations were 1 and $10 \mathrm{mM}$, after which insulin content was extracted with acid/ethanol. The samples were stored at $-20^{\circ} \mathrm{C}$ and assayed by chemiluminescent immunoassay (STELLUX, Alpco Diagnostics) or electro-chemiluminescent immunoassay (Human Insulin Kit, Meso Scale Diagnostics). Experiments were performed in triplicate, and the averaged values were used for analyses. Patch-clamp measurement of Kv currents and exocytotic responses in single HEK293, INS $832 / 13$, or human $\beta$ cells, the latter identified by positive insulin immunostaining following the experiment, were performed at $32^{\circ} \mathrm{C}$ to $35^{\circ} \mathrm{C}$ as described previously (33) using a HEKA EPC10 amplifier and PatchMaster Software (HEKA).

TIRFM imaging. All TIRF imaging used a cellTIRF motorized system (IX83P2ZF, Olympus, Canada) with a $100 \times / 1.49$ NA TIRFM objective, a Photometrics Evolve 512 camera, and Metamorph Imaging software (Molecular Devices). Excitation was at $491 \mathrm{~nm}$ (LAS-491-50, Olympus) and $561 \mathrm{~nm}$ (LAS-56150, Olympus) with a quad filter passing through a major dichroic and band-pass filter (405/488/561/640, Chroma Technology). Penetration depth was set to $105 \mathrm{~nm}$, calculated using the existing angle of the laser and assuming a refractive index of 1.37 . Emission was collected through band-pass filters of $525 / 25 \mathrm{~nm}$ and 605/26 nm for excitations of 488 and $561 \mathrm{~nm}$, respectively. Images were acquired sequentially with single laser excitation to minimize potential bleed through.

Single $\beta$ cells from dispersed human islets were cultured on 25-mm round coverslips from Electron Microscopy Sciences (catalog 72225-01) overnight in the human islet media describe above. Live-cell acquisition was at $5 \mathrm{~Hz}$ with a $200-\mathrm{ms}$ exposure at $35^{\circ} \mathrm{C}$. Before acquisition, cells were preincubated (30 minutes) in bath containing (in $\mathrm{mM}$ ) $138 \mathrm{NaCl}, 5.6 \mathrm{KCl}, 1.2 \mathrm{MgCl}_{2}, 2.6 \mathrm{CaCl}_{2}, 5 \mathrm{NaHCO}_{3}, 1$ glucose, and $5 \mathrm{HEPES}$ ( $\mathrm{pH} 7.4$ with $\mathrm{NaOH}$ ) and then exposed to $5 \mathrm{mM}$ glucose upon recording. In glucose stimulation experiments, the buffer contained $16.7 \mathrm{mM}$ glucose. For $\mathrm{KCl}$ stimulation, the buffer instead contained $30 \mathrm{mM} \mathrm{KCl}$, which replaced an equimolar amount of $\mathrm{NaCl}$. Fusion events, indicated by abrupt brightening (ratio of peak fluorescence to background >1.3) and then disappearance of NPY-EGFP fluorescence, were selected and analyzed with a compiled MATLAB-based (MathWorks) analysis software (18) within the membrane area (the authors provided their software). Docked granules were detected using a "local maxima" or a weighted centroid method (within a range of $4 \times 4$ pixels, $0.6328 \times 0.6328 \mu \mathrm{m}$; ref. 18). Exocytosis events occurring around docking granules were manually selected following overlay of fusion events with identified sites of membrane-resident granules at the start of recordings. 
Spatial analysis was performed in MATLAB, 2018a (MathWorks). Voronoi polygons were used to separate each fusion event. The standard deviation of resulting areas divided by the area mean is indicative of the degree of spatial heterogeneity of fusion events. We refer to this, described in Yuan et al. as a "uniform index" (18), as a CI because increases represent greater compartmentalization of fusion events. These observed values were compared against random simulations run 100 times with the same number of fusion events and the same $c \times \times \times$ ell boundaries. Exocytosis hotspots, recognized by MATLAB, were run with a threshold value of $0.6328 \mu \mathrm{m}$, which is less than 4 pixels and represents the minimum resolvable distance to distinguish 2 granule fusion sites in our system. The percentage of events at hotspots was calculated as the number of fusion events occurring at hotspots divided by the total fusion events and multiplied by 100 . The hotspot density (no./100 $\mu \mathrm{m}^{2}$ ) was calculated as the number of hotspots normalized to cell footprint area. Hotspot visualization heatmaps were generated through interpolation (MATLAB "v4" interpolation method) using the number of events as the third dimension on a 1-pixel resolution grid.

Statistics. Data analysis was performed using Fit Master (HEKA Electronik), Origin Lab (v7.0), and GraphPad Prism (v6.0c). All data are shown as the mean \pm SEM. Statistical outliers were identified and removed by an unbiased robust regression followed by outlier identification test. Normally distributed data were analyzed by 2-tailed Student's $t$ test (for 2 groups) or ANOVA and Bonferroni's posttest (for multiple groups). Data that failed normality tests were analyzed by nonparametric Mann-Whitney test (for 2 groups) or Kruskal-Wallis 1-way ANOVA followed by Mann-Whitney posttest (for multiple groups). A $P$ value of less than 0.05 was considered significant.

Study approval. All human islet studies were approved by the Human Research Ethics Board (Pro00013094; Pro00001754) at the University of Alberta and all families of organ donors provided written informed consent.

\section{Author contributions}

JF, JMG, XD, GP, KS, AFS, AB, RK, DGA, and JEMF conducted the research and analyzed the data. JF, HYG, and PEM conceived the study. JF and PEM wrote the manuscript. All authors edited and approved this version.

\section{Acknowledgments}

We wish to thank Yongdeng Zhang (Yale University) for providing the computer-assisted analysis software and advice on data analysis. The authors thank the Human Organ Procurement and Exchange and Trillium Gift of Life Network programs for their efforts in procuring pancreases for research. The authors also thank James Lyon and Nancy Smith (Alberta Diabetes Institute IsletCore, University of Alberta) for work isolating human islets for research. Human islet isolations for research were supported by the Alberta Diabetes Foundation and the University of Alberta. Research was funded by a Foundation Grant from the Canadian Institutes of Health Research (grant 148451) to PEM.

Address correspondence to: Patrick MacDonald, Alberta Diabetes Institute, LKS Centre, Room 6-126, University of Alberta, Edmonton, Alberta, Canada, T6G 2E1. Phone: 780.492.8063; Email: pmacdonald@ualberta.ca.

1. Tokarz VL, MacDonald PE, Klip A. The cell biology of systemic insulin function. J Cell Biol. 2018;217(7):2273-2289.

2. Kahn SE, Cooper ME, Del Prato S. Pathophysiology and treatment of type 2 diabetes: perspectives on the past, present, and future. Lancet. 2014;383(9922):1068-1083.

3. Schwartz SS, Epstein S, Corkey BE, Grant SF, Gavin JR, Aguilar RB. The time is right for a new classification system for diabetes: rationale and implications of the $\beta$-cell-centric classification schema. Diabetes Care. 2016;39(2):179-186.

4. Ha J, Satin LS, Sherman AS. A mathematical model of the pathogenesis, prevention, and reversal of type 2 diabetes. Endocrinology. 2016;157(2):624-635.

5. Butler AE, Janson J, Bonner-Weir S, Ritzel R, Rizza RA, Butler PC. $\beta$-Cell deficit and increased $\beta$-cell apoptosis in humans with type 2 diabetes. Diabetes. 2003;52(1):102-110.

6. Del Guerra S, et al. Functional and molecular defects of pancreatic islets in human type 2 diabetes. Diabetes. 2005;54(3):727-735.

7. Deng S, et al. Structural and functional abnormalities in the islets isolated from type 2 diabetic subjects. Diabetes. 2004;53(3):624-632.

8. Ostenson CG, Gaisano H, Sheu L, Tibell A, Bartfai T. Impaired gene and protein expression of exocytotic soluble N-ethylmaleimide attachment protein receptor complex proteins in pancreatic islets of type 2 diabetic patients. Diabetes. 2006;55(2):435-440

9. Andersson SA, et al. Reduced insulin secretion correlates with decreased expression of exocytotic genes in pancreatic islets from 
patients with type 2 diabetes. Mol Cell Endocrinol. 2012;364(1-2):36-45.

10. Rosengren $\mathrm{AH}$, et al. Reduced insulin exocytosis in human pancreatic $\beta$-cells with gene variants linked to type 2 diabetes. Diabetes. 2012;61(7):1726-1733.

11. Ferdaoussi M, et al. Isocitrate-to-SENP1 signaling amplifies insulin secretion and rescues dysfunctional $\beta$ cells. J Clin Invest. 2015;125(10):3847-3860.

12. Gandasi NR, Yin P, Omar-Hmeadi M, Ottosson Laakso E, Vikman P, Barg S. Glucose-dependent granule docking limits insulin secretion and is decreased in human type 2 diabetes. Cell Metab. 2018;27(2):470-478.e4.

13. Almaça J, Liang T, Gaisano HY, Nam HG, Berggren PO, Caicedo A. Spatial and temporal coordination of insulin granule exocytosis in intact human pancreatic islets. Diabetologia. 2015;58(12):2810-2818.

14. Low JT, et al. Insulin secretion from $\beta$ cells in intact mouse islets is targeted towards the vasculature. Diabetologia. 2014;57(8):1655-1663.

15. Ohara-Imaizumi M, et al. ELKS/Voltage-dependent $\mathrm{Ca}^{2+}{ }_{\text {}}$ channel- $\beta$ subunit module regulates polarized $\mathrm{ca}^{2+}$ influx in pancreatic $\beta$ cells. Cell Rep. 2019;26(5):1213-1226.e7.

16. Gan WJ, et al. Local integrin activation in pancreatic $\beta$ cells targets insulin secretion to the vasculature. Cell Rep. 2018;24(11):2819-2826.e3.

17. Gan WJ, et al. Cell polarity defines three distinct domains in pancreatic $\beta$-cells. J Cell Sci. 2017;130(1):143-151.

18. Yuan T, Lu J, Zhang J, Zhang Y, Chen L. Spatiotemporal detection and analysis of exocytosis reveal fusion "hotspots" organized by the cytoskeleton in endocrine cells. Biophys $J$. 2015;108(2):251-260.

19. Greitzer-Antes D, et al. Kv2.1 clusters on $\beta$-cell plasma membrane act as reservoirs that replenish pools of newcomer insulin granule through their interaction with syntaxin-3. J Biol Chem. 2018;293(18):6893-6904.

20. Lam PP, et al. Munc18b is a major mediator of insulin exocytosis in rat pancreatic $\beta$-cells. Diabetes. 2013;62(7):2416-2428

21. Takahashi N, Kishimoto T, Nemoto T, Kadowaki T, Kasai H. Fusion pore dynamics and insulin granule exocytosis in the pancreatic islet. Science. 2002;297(5585):1349-1352.

22. Kwan EP, Gaisano HY. Glucagon-like peptide 1 regulates sequential and compound exocytosis in pancreatic islet $\beta$-cells. Diabetes. 2005;54(9):2734-2743.

23. Barg S, Knowles MK, Chen X, Midorikawa M, Almers W. Syntaxin clusters assemble reversibly at sites of secretory granules in live cells. Proc Natl Acad Sci U S A. 2010;107(48):20804-20809.

24. Knowles MK, Barg S, Wan L, Midorikawa M, Chen X, Almers W. Single secretory granules of live cells recruit syntaxin-1 and synaptosomal associated protein 25 (SNAP-25) in large copy numbers. Proc Natl Acad Sci U S A. 2010;107(48):20810-20815

25. Ohara-Imaizumi M, Nishiwaki C, Nakamichi Y, Kikuta T, Nagai S, Nagamatsu S. Correlation of syntaxin-1 and SNAP-25 clusters with docking and fusion of insulin granules analysed by total internal reflection fluorescence microscopy. Diabetologia. 2004;47(12):2200-2207.

26. Hoppa MB, et al. Chronic palmitate exposure inhibits insulin secretion by dissociation of Ca. Cell Metab. 2011;13(4):487.

27. Collins SC, et al. Progression of diet-induced diabetes in C57BL6J mice involves functional dissociation of Ca2(+) channels from secretory vesicles. Diabetes. 2010;59(5):1192-1201.

28. Gandasi NR, et al. $\mathrm{Ca}^{2+}$ channel clustering with insulin-containing granules is disturbed in type 2 diabetes. JClin Invest. 2017;127(6):2353-2364.

29. Rorsman P, Ashcroft FM. Pancreatic $\beta$-cell electrical activity and insulin secretion: of mice and men. Physiol Rev. 2018;98(1):117-214

30. Braun M, et al. Voltage-gated ion channels in human pancreatic beta-cells: electrophysiological characterization and role in insulin secretion. Diabetes. 2008;57(6):1618-1628.

31. O'Connell KM, Tamkun MM. Targeting of voltage-gated potassium channel isoforms to distinct cell surface microdomains. J Cell Sci. 2005;118(pt 10):2155-2166.

32. Fu J, et al. Kv2.1 Clustering Contributes to Insulin Exocytosis and Rescues Human $\beta$-Cell Dysfunction. Diabetes. 2017;66(7):1890-1900

33. Dai XQ, et al. The voltage-dependent potassium channel subunit Kv2.1 regulates insulin secretion from rodent and human islets independently of its electrical function. Diabetologia. 2012;55(6):1709-1720.

34. Leung YM, Kwan EP, Ng B, Kang Y, Gaisano HY. SNAREing voltage-gated $\mathrm{K}^{+}$and ATP-sensitive $\mathrm{K}^{+}$channels: tuning $\beta$-cell excitability with syntaxin-1A and other exocytotic proteins. Endocr Rev. 2007;28(6):653-663.

35. Johnson B, Leek AN, Solé L, Maverick EE, Levine TP, Tamkun MM. Kv2 potassium channels form endoplasmic reticulum/ plasma membrane junctions via interaction with VAPA and VAPB. Proc Natl Acad Sci U S A. 2018;115(31):E7331-E7340.

36. Singer-Lahat D, et al. $\mathrm{K}^{+}$channel facilitation of exocytosis by dynamic interaction with syntaxin. J Neurosci. 2007;27(7):1651-1658

37. Plant LD, Dowdell EJ, Dementieva IS, Marks JD, Goldstein SA. SUMO modification of cell surface Kv2.1 potassium channels regulates the activity of rat hippocampal neurons. J Gen Physiol. 2011;137(5):441-454.

38. Dai XQ, et al. SUMOylation regulates insulin exocytosis downstream of secretory granule docking in rodents and humans. Diabetes. 2011;60(3):838-847.

39. Marchetti P, et al. Pancreatic islets from type 2 diabetic patients have functional defects and increased apoptosis that are ameliorated by metformin. J Clin Endocrinol Metab. 2004;89(11):5535-5541.

40. Lyon J, et al. Research-focused isolation of human islets from donors with and without diabetes at the Alberta Diabetes Institute IsletCore. Endocrinology. 2016;157(2):560-569.

41. Gembal M, Gilon P, Henquin JC. Evidence that glucose can control insulin release independently from its action on ATP-sensitive K+ channels in mouse B cells. J Clin Invest. 1992;89(4):1288-1295.

42. Brüning D, Reckers K, Drain P, Rustenbeck I. Glucose but not $\mathrm{KCl}$ diminishes submembrane granule turnover in mouse $\beta$-cells J Mol Endocrinol. 2017;59(3):311-324.

43. Ohara-Imaizumi M, Nakamichi Y, Tanaka T, Ishida H, Nagamatsu S. Imaging exocytosis of single insulin secretory granules with evanescent wave microscopy: distinct behavior of granule motion in biphasic insulin release. J Biol Chem. 2002;277(6):3805-3808

44. O'Connell KM, Rolig AS, Whitesell JD, Tamkun MM. Kv2.1 potassium channels are retained within dynamic cell surface 
microdomains that are defined by a perimeter fence. J Neurosci. 2006;26(38):9609-9618.

45. Dai XQ, Kolic J, Marchi P, Sipione S, Macdonald PE. SUMOylation regulates Kv2.1 and modulates pancreatic $\beta$-cell excitability. J Cell Sci. 2009;122(pt 6):775-779.

46. Leung YM, et al. Syntaxin 1A binds to the cytoplasmic C terminus of Kv2.1 to regulate channel gating and trafficking. $J$ Biol Chem. 2003;278(19):17532-17538.

47. MacDonald PE, et al. Synaptosome-associated protein of 25 kilodaltons modulates Kv2.1 voltage-dependent $\mathrm{K}(+)$ channels in neuroendocrine islet $\beta$-cells through an interaction with the channel N terminus. Mol Endocrinol. 2002;16(11):2452-2461.

48. Benson MD, et al. SUMO modification regulates inactivation of the voltage-gated potassium channel Kv1.5. Proc Natl Acad Sci U S A. 2007;104(6):1805-1810.

49. Zhu X, et al. Microtubules negatively regulate insulin secretion in pancreatic $\beta$ cells. Dev Cell. 2015;34(6):656-668

50. Veluthakal R, Chepurny OG, Leech CA, Schwede F, Holz GG, Thurmond DC. Restoration of glucose-stimulated Cdc42-Pak1 activation and insulin secretion by a selective Epac activator in type 2 diabetic human islets. Diabetes. 2018;67(10):1999-2011.

51. Ferrannini E, Gastaldelli A, Miyazaki Y, Matsuda M, Mari A, DeFronzo RA. $\beta$-Cell function in subjects spanning the range from normal glucose tolerance to overt diabetes: a new analysis. J Clin Endocrinol Metab. 2005;90(1):493-500.

52. Cai EP, et al. In vivo role of focal adhesion kinase in regulating pancreatic $\beta$-cell mass and function through insulin signaling, actin dynamics, and granule trafficking. Diabetes. 2012;61(7):1708-1718.

53. Leung YM, et al. Syntaxin 1A binds to the cytoplasmic C terminus of Kv2.1 to regulate channel gating and trafficking. J Biol Chem. 2003;278(19):17532-17538

54. Zhu D, et al. Syntaxin-3 regulates newcomer insulin granule exocytosis and compound fusion in pancreatic $\beta$ cells. Diabetologia. 2013;56(2):359-369.

55. Lyon J. et al. Isolation of human pancreatic islets of Langerhans for research v2 (protocols.io.xgsfjwe). protocols.io. doi:10.17504/protocols.io.xgsfjwe.

56. Hohmeier HE, Mulder H, Chen G, Henkel-Rieger R, Prentki M, Newgard CB. Isolation of INS-1-derived cell lines with robust ATP-sensitive $\mathrm{K}^{+}$channel-dependent and -independent glucose-stimulated insulin secretion. Diabetes. 2000;49(3):424-430

57. Spigelman A. Static glucose-stimulated insulin secretion (GSIS) protocol - human islets v2 (protocols.io.wy4ffyw). protocols.io. doi:10.17504/protocols.io.wy4ffyw. 